\title{
Theoretical Study of the Spectral Response in Near Infrared of III-V Photodetectors Based on Al, Ga, In, and Sb: The Window Layer Effect
}

\author{
Mamadou Dia, Babacar Mbow, EL Hadji Mamadou Keita, Abdoul Aziz Correa, \\ Mamadou Lamine Sow
}

Laboratory of Semiconductors and Solar Energy, Physics Department, Faculty of Science and TechnologyUniversity Cheikh Anta DIOP, Dakar, Senegal

\author{
Email address: \\ diamohamed186@gmail.com (M. Dia),bbmbow@gmail.com (B. Mbow)
}

\section{To cite this article:}

Mamadou Dia, Babacar Mbow, EL Hadji Mamadou Keita, Abdoul Aziz Correa, Mamadou Lamine Sow. Theoretical Study of the Spectral Response in Near Infrared of III-V Photodetectors Based on Al, Ga, In, and Sb: The Window Layer Effect. International Journal of Materials Science and Applications. Vol. 6, No. 1, 2017, pp. 45-53. doi: 10.11648/j.ijmsa.20170601.17

Received: December 8, 2016; Accepted: December 20, 2016; Published: January 18, 2017

\begin{abstract}
The spectral responses are particularly important for the design of photodetectors operating in the wavelength range between $0,78 \mu \mathrm{m}$ to $2,6 \mu \mathrm{m}$. To elaborate each device; we purpose a theoretical model to calculate the internal quantum efficiency. The theoretical curves of the internal quantum efficiency are obtained, by simulation to define the geometrical and photoelectric parameters, of the photodetectors devices. The modelling of the various devices allows us to analyze the situation at surface and in volume of each model. The results and the theoretical models, of the heterostructures based on $\mathrm{Ga}_{1-\mathrm{x}} \mathrm{In}_{\mathrm{x}} \mathrm{Sb}, \mathrm{Ga}_{1-\mathrm{y}} \mathrm{Al} \mathrm{y}_{\mathrm{y}} \mathrm{Sb}$ grown on GaSb substrate, with window layer are shown after simulation of the internal quantum efficiency and sensitivity of each model. Analysis of these results allowed us to appreciate which of these models is more efficient and to identify the photoelectric parameters to improve for better internal quantum efficiency. We found that the presence of the window layer significantly reduces the losses by recombination thereby improving the photodetector performance.
\end{abstract}

Keywords: III-V Photodetectors, Heterostructures, Near-Infrared, Quantum Efficiency, Spectral Response, Window Layer

\section{Introduction}

The GaSb-based semiconductors materials family including $\mathrm{GaSb}, \mathrm{InSb}$ and AlSb, permits large flexibility in the design of novel functional materials and devices [1]. Several III-V semiconductors materials currently hold the attention for the development of photodetectors in near-infrared [2]. Among them, the heterostructures based on antimony had attracted great attention, to develop infrared detectors. Very promising prospects offer, to these semiconductors, particularly GaSb, GaInSb, GaAlSb and associated materials, because of their outstanding intrinsic properties. They are in fact endowed a high electronic mobility and, often, a direct bandgap energy [3] making them components of choice for optoelectronic devices. In some of earth observation satellites from space, imaging in the infrared band medium allows monitoring the spread of wetlands, desertification and maturity of crops. Due to the current trend to reducing the dimensions of the devices, the surfaces and interfaces have influence increasingly predominant on their performances.

In this work, we seek to develop photodetectors that enable better detection in the wavelength range $0,78 \mu \mathrm{m}$ to $2,6 \mu \mathrm{mby}$ determining the geometrical parameters (thicknesses of the various regions) and the photoelectric parameters (recombination velocities and diffusion length) of each model adapted to the design of the photodetector. For this, we use the analysis of the internal quantum efficiency and of the sensitivity to study the photoelectric properties. The geometrical and photoelectric parameters of each photodetector are defined by simulation by adopting appropriate theoretical models.

Models of photodetector devices used in this work are the heterostructures $\mathrm{Ga}_{1-\mathrm{x}} \mathrm{In}_{\mathrm{x}} \mathrm{Sb}_{\mathrm{p}} / \mathrm{Ga}_{1-\mathrm{x}} \mathrm{In}_{\mathrm{x}} \mathrm{Sb}_{\mathrm{n}}$ grown on $\mathrm{GaSb}_{\mathrm{N}}$ substrate, $\mathrm{Ga}_{1-\mathrm{y}} \mathrm{Al}_{\mathrm{y}} \mathrm{Sb}_{\mathrm{p}} / \mathrm{Ga}_{1-\mathrm{x}} \mathrm{In}_{\mathrm{x}} \mathrm{Sb}_{\mathrm{n}}$ grown on $\mathrm{GaSb}_{\mathrm{N}}$ substrate and, $\mathrm{Ga}_{1-\mathrm{y}} \mathrm{Al}_{\mathrm{y}} \mathrm{Sb}_{\mathrm{P}} / \mathrm{Ga}_{1-\mathrm{x}} \mathrm{In}_{\mathrm{x}} \mathrm{Sb}_{\mathrm{n}} / \mathrm{Ga}_{1-\mathrm{x}} \mathrm{In}_{\mathrm{x}} \mathrm{Sb}_{\mathrm{n}}$ deposited on $\mathrm{GaSb}_{\mathrm{N}}$ substrate, with $\mathrm{Ga}_{1-\mathrm{y}} \mathrm{Al}_{\mathrm{y}} \mathrm{Sb}_{\mathrm{p}}$ as window layer and $\mathrm{x}$ equal to 
$18 \%$, y equal to $8 \%$.

\section{Modelling}

For each device, a theoretical analysis of the determination of the quantum efficiency is based upon the influence of geometrical and photoelectric parameters, and recombination effects at surface, and in volume of the minority carriers generated by illumination. Each absorbed photon creates an electron-hole pair and, the minority carriers diffuse to the region where they are majority, before being collected. We assume that there is no energy discontinuity due to electronic affinity of GaInSb, GaAlSb and GaSb in the material. The two regions on either side of the junction are uniformly doped then, there is no electric field outside the space charge zone.

\subsection{The P-N Heterojunction Grown on GaSb Substrate}

In order, to simulate a model corresponding to a $p-n$ structure deposited on $\mathrm{GaSbN}$ substrate (Figure 1), we assume that the junction is located between the first two layers (p-type and n-type Figure 1), and that the thickness of substrate is infinitely greater than the other geometrical parameters. Luquet et al and Laugier have used a similar model to calculate the efficiency in the base [4]. The capital letters $(\mathrm{P}, \mathrm{N})$ represent the large-gap materials and the lowercase letters $(\mathrm{p}$, n) the low-gap materials, for the same type of doping [5]. We will determine the current densities in each region to deduce the internal quantum efficiency. In the calculations, we will limit ourselves to heterojunction models. The geometrical characteristics are given by the Figure 1 .

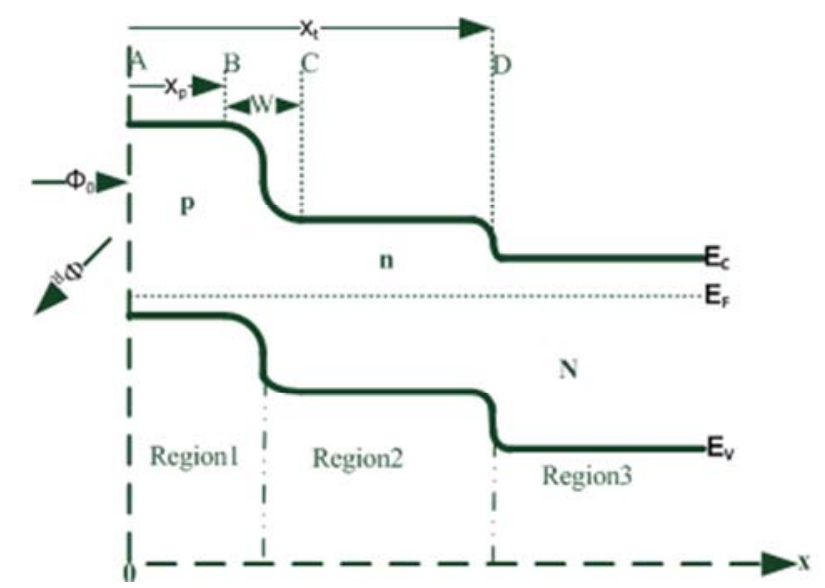

Figure 1. Energy band diagram of p-n-N heterojunction grown on $G a S b_{N}$ substrate.

\subsubsection{Calculation of the $J_{n}$ Current Density of Electron Diffusion in Front Layer}

This current density is obtained from the following continuity equation [4]:

$$
\frac{d^{2} \Delta n_{1}}{d x^{2}}-\frac{\Delta n_{1}}{\left(L n_{1}\right)^{2}}=-\frac{\alpha_{1}(1-R) \Phi_{0} e^{-\alpha_{1} x_{p}}}{D n_{1}}
$$

where $\Phi_{0}$ is the incident photon flux density at the surface of the front layer (area $\mathrm{AB}$ Figure 1), $\mathrm{R}$ is the reflection coefficient at the surface of the front layer, $\operatorname{Ln}_{1}$ the electron diffusion length, $\alpha_{1}$ the absorption coefficient of the front layer, $\mathrm{Dn}_{1}$ the electron diffusion coefficient in the region 1 and $\Delta \mathrm{n}_{1}$ the electron charge density evolution in the $\mathrm{AB}$ area.

The solution of this equation is in the form:

$$
\begin{aligned}
& \Delta n_{1}(x)=A e^{-x / L n_{1}}+B e^{x / L n 1}+K_{1} e^{-\alpha_{1} x} \\
& \text { With } K_{1}=-\frac{\left(L n_{1}\right)^{2} \alpha_{1}(1-R) \Phi_{0}}{D n_{1}\left[\left(\alpha_{1}\right)^{2}\left(L n_{1}\right)^{2}-1\right]}
\end{aligned}
$$

The constants A and B are obtained from the following boundary conditions

$$
\begin{gathered}
\frac{d \Delta n_{1}}{d x}=\frac{S n_{1}}{D n_{1}} \Delta n_{1} \text { for } x=0 \\
\Delta n_{1}=0 \text { for } x=x_{p}
\end{gathered}
$$

The current density of electron diffusion in region 1 (zone AB Fig 1) is defined by [4]:

$$
\begin{gathered}
J_{n}=\left.e D n_{1} \frac{d \Delta n_{1}}{d x}\right|_{x=x_{p}} \\
J_{n}=-\frac{e(1-R) \Phi_{0} \alpha_{1} L n_{1}}{\left[\left(\alpha_{1}\right)^{2}\left(L n_{1}\right)-1\right]} \\
{\left[\begin{array}{l}
L n_{1} \alpha_{1}+\frac{S n_{1} L n_{1}}{D n_{1}}- \\
{\left[\begin{array}{l}
\left.\sinh \left(\frac{x_{p}}{L n_{1}}\right)+\frac{S n_{1} L n_{1}}{D n_{1}} \cosh \left(\frac{x_{p}}{L n_{1}}\right)\right] e^{-\alpha_{1} x_{p}} \\
\cosh \left(\frac{x_{p}}{L n_{1}}\right)+\frac{S n_{1} L n_{1}}{D n_{1}} \sinh \left(\frac{x_{p}}{L n_{1}}\right) \\
-\alpha_{1} L n_{1} e^{-\alpha_{1} x_{p}}
\end{array}\right]}
\end{array}\right.}
\end{gathered}
$$

This photocurrent is due to the absorption of photons in the layer $\mathrm{P}$ of $\mathrm{x}_{\mathrm{p}}$ depth (area AB in Figure 1). This photocurrent is essentially an electron current whose the same expression is given by A. Joullie et al [6].

The spectral response or the internal quantum efficiency of a photodetector is defined as the ratio of the number of collected charge carriers to the number of absorbed photons. It is expressed by[4], [6-8]:

$$
\eta_{T}=\frac{J_{p h}}{q(1-R) \Phi_{0}}
$$

where $\mathrm{q}$ is the elementary charge of the minority carrier, $\mathrm{J}_{\mathrm{ph}}$ the density of the total photocurrent of the detector. For each radiation, this internal quantum efficiency, results to components generated at different depths. The contribution of electrons generated in the transmitter (Figure 1 area $\mathrm{AB}$ ), and collected by the p-n junction (Figure 1) is described by the formula $(9)$. 


$$
\begin{aligned}
\eta_{f}=\frac{\alpha_{1} L n_{1}}{\left[\left(\alpha_{1}\right)^{2}\left(L n_{1}\right)-1\right]} \\
{\left[\begin{array}{l}
\frac{L n_{1} \alpha_{1}+\frac{S n_{1} L n_{1}}{D n_{1}}-}{\left[\sinh \left(\frac{x_{p}}{L n_{1}}\right)+\frac{S n_{1} L n_{1}}{D n_{1}} \cosh \left(\frac{x_{p}}{L n_{1}}\right)\right] e^{-\alpha_{1} x_{p}}} \\
\cosh \left(\frac{x_{p}}{L n_{1}}\right)+\frac{S n_{1} L n_{1}}{D n_{1}} \sinh \left(\frac{x_{p}}{L n_{1}}\right)
\end{array}\right] }
\end{aligned}
$$

This expression is almost identical to that of Le Nam, M. Rodot and al [9]

\subsubsection{Calculation of the $J_{p}$ Hole Diffusion Current Density in Base (Region 2)}

This current density is obtained from the following continuity equations [4]:

$$
\begin{gathered}
\frac{d^{2} \Delta p_{2}}{d x^{2}}-\frac{\Delta p_{2}}{\left(L p_{2}\right)^{2}}= \\
-\frac{\alpha_{2}(1-R) \Phi_{0} e^{-\left(\alpha_{1}-\alpha_{2}\right)\left(x_{p}+w_{1}\right)} e^{-\alpha_{2} x}}{D p_{2}} \\
\frac{d^{2} \Delta p_{3}}{d x^{2}}-\frac{\Delta p_{3}}{\left(L p_{3}\right)^{2}}= \\
-\frac{\alpha_{3}(1-R) \Phi_{0} e^{-\left(\alpha_{1}-\alpha_{2}\right)\left(x_{p}+w_{1}\right)} e^{-\left(\alpha_{2}-\alpha_{3}\right) x_{t}} e^{-\alpha_{3} x}}{D p_{3}}
\end{gathered}
$$

where $L p_{2}$ and $L p_{3}$ are the diffusion lengths of holes, respectively in the regions 2 and $3, \alpha_{2}$ and $\alpha_{3}$ are the absorption coefficients of the layers 2 and 3 and $\mathrm{Dp}_{2}$ and $\mathrm{Dp}_{3}$, are the diffusion coefficients of the holes in regions 2 and 3 , and $\Delta \mathrm{p}_{2}$ and $\Delta \mathrm{p}_{3}$ are the evolutions of the charge density of the holes in the regions 2 and 3 .

The solutions of these equations are in the form:

$$
\begin{gathered}
\Delta p_{2}(x)=C e^{-x / L p_{2}}+D e^{x / L p_{2}}+K_{2} e^{-\alpha_{2} x} \\
\text { with } K_{2}=-\frac{\left(L p_{2}\right)^{2} \alpha_{2}(1-R) \Phi_{0} e^{-\left(\alpha_{1}-\alpha_{2}\right)\left(x_{p}+w_{1}\right)}}{D p_{2}\left[\left(\alpha_{2}\right)^{2}\left(L p_{2}\right)^{2}-1\right]} \\
\Delta p_{3}(x)=M e^{-x / L p_{3}}+N e^{x / L p_{3}}+K_{3} e^{-\alpha_{3} x} \\
\text { with } K_{3}=-\frac{e^{-\left(\alpha_{1}-\alpha_{2}\right)\left(x_{p}+w_{1}\right)} e^{-\left(\alpha_{2}-\alpha_{3}\right) x_{t}}}{D p_{3}\left[\left(\alpha_{3}\right)^{2}\left(L p_{3}\right)^{2}-1\right]}
\end{gathered}
$$

The constants $\mathrm{C}, \mathrm{D}, \mathrm{M}$ and $\mathrm{N}$ are obtained from the following boundary conditions: [4]

$$
\begin{gathered}
\Delta p_{2}=0 \text { for } x=x_{p}+w \\
\Delta p_{2}=\Delta p_{3} \text { for } x=x_{t} \\
D p_{2} \frac{d \Delta p_{2}}{d x}=D p_{3} \frac{d \Delta p_{3}}{d x} \text { for } x=x_{t} \\
\Delta p_{3}=0 \text { for } x \approx \infty
\end{gathered}
$$

The diffusion current density of the holes in region 2 (zone CD Figure 1) is defined by [4]:

$$
\begin{aligned}
& J_{p}=-\left.e D p_{2} \frac{d \Delta p_{2}}{d x}\right|_{x=x_{p}+w} \\
& J_{p}=-\frac{e(1-R) \Phi_{0} \alpha_{2} L p_{2}}{\left[\left(\alpha_{2}\right)^{2}\left(L p_{2}\right)^{2}-1\right]} e^{-\left(\alpha_{1}-\alpha_{2}\right)\left(x_{p}+w_{1}\right)} \\
& {\left[\begin{array}{l}
\left(\begin{array}{l}
\left.\alpha_{2} L p_{2}-\frac{D p_{3} L p_{2}}{D p_{2} L p_{3}}\right) e^{-\alpha_{2} x_{t}}+ \\
\sinh \left(\frac{x_{t}-\left(x_{p}+w\right)}{L p_{2}}\right)+ \\
\left.\frac{D p_{3} L p_{2}}{D p_{2} L p_{3}} \cosh \left(\frac{x_{t}-\left(x_{p}+w\right)}{L p_{2}}\right)\right] e^{-\alpha_{2}\left(x_{P}+w\right)} \\
{\left[\begin{array}{l}
\cosh \left(\frac{x_{t}-\left(x_{p}+w\right)}{L p_{2}}\right)+ \\
\frac{D p_{3} L p_{2}}{D p_{2} L p_{3}} \sinh \left(\frac{x_{t}-\left(x_{p}+w\right)}{L p_{2}}\right)
\end{array}\right]}
\end{array}\right] \\
\left.-\alpha_{2} L p_{2} e^{-\alpha_{2}\left(x_{P}+w\right)}\right]
\end{array}\right]} \\
& -\frac{e(1-R) \Phi_{0} \alpha_{3} L p_{3}}{\left[\left(\alpha_{3}\right)^{2}\left(L p_{3}\right)^{2}-1\right]} e^{-\left(\alpha_{1}-\alpha_{2}\right)\left(x_{p}+w_{1}\right)} \\
& {\left[\begin{array}{l}
{\left[\frac{\left(1-\alpha_{3} L p_{3}\right) e^{-\alpha_{2} x_{t}}}{\cosh \left(\frac{x_{t}-\left(x_{p}+w\right)}{L p_{2}}\right)+}\right]} \\
\left.\frac{D p_{3} L p_{2}}{D p_{2} L p_{3}} \sinh \left(\frac{x_{t}-\left(x_{p}+w\right)}{L p_{2}}\right)\right]
\end{array}\right]}
\end{aligned}
$$

From equations (8) and (21), we get the expression of the 
internal quantum efficiency of the base (formula 22), which describes the contribution of holes generated in base (CD areaFigure 1) and collected by the $\mathrm{p}-\mathrm{n}$ junction:

$$
\begin{aligned}
& \eta_{b}=-\frac{\alpha_{2} L p_{2}}{\left[\left(\alpha_{2}\right)^{2}\left(L p_{2}\right)^{2}-1\right]} e^{-\left(\alpha_{1}-\alpha_{2}\right)\left(x_{p}+w_{1}\right)} \\
& {\left[\begin{array}{l}
\left(\alpha_{2} L p_{2}-\frac{D p_{3} L p_{2}}{D p_{2} L p_{3}}\right) e^{-\alpha_{2} x_{t}}+ \\
{\left[\begin{array}{l}
\sinh \left(\frac{x_{t}-\left(x_{p}+w\right)}{L p_{2}}\right)+ \\
\left.\frac{D p_{3} L p_{2}}{D p_{2} L p_{3}} \cosh \left(\frac{x_{t}-\left(x_{p}+w\right)}{L p_{2}}\right)\right] e^{-\alpha_{2}\left(x_{P}+w\right)}
\end{array}\right]+\left[\begin{array}{l}
\cosh \left(\frac{x_{t}-\left(x_{p}+w\right)}{L p_{2}}\right) \\
{\left[\frac{D p_{3} L p_{2}}{D p_{2} L p_{3}} \sinh \left(\frac{x_{t}-\left(x_{p}+w\right)}{L p_{2}}\right)\right.}
\end{array}\right]} \\
-\alpha p_{2} e^{-\alpha_{2}\left(x_{P}+w\right)} \\
\alpha \alpha_{2} L p_{3}
\end{array}\right]} \\
& -\frac{\alpha_{3} L p_{3}}{\left[\left(\alpha_{3}\right)^{2}\left(L p_{3}\right)^{2}-1\right]} e^{-\left(\alpha_{1}-\alpha_{2}\right)\left(x_{p}+w_{1}\right)} \\
& {\left[\begin{array}{l}
{\left[\begin{array}{l}
\cosh \left(\frac{x_{t}-\left(x_{p}+w\right)}{L p_{2}}\right)+ \\
\frac{D p_{3} L p_{2}}{D p_{2} L p_{3}} \sinh \left(\frac{x_{t}-\left(x_{p}+w\right)}{L p_{2}}\right)
\end{array}\right]}
\end{array}\right]}
\end{aligned}
$$

\subsubsection{Calculation of the Diffusion Current Density in the Space Charge Zone (Jzce)}

In the region of space charge (area BC Figure1), the electron-hole pairs are generated by the interaction with photons and dissociated by the electric field. Electrons are sent to the $n$ region, and the holes to the $\mathrm{p}$ area.

At any point $\mathrm{x}$ of the space-charge area, there is a current density which is the sum of the electron current density generated between $x_{p}$ and $x$ with the current density of holes generated between $x$ and $x_{p}+w[10]$.

The contribution of the current density in space-charge area is given by [10]:

$$
J_{g ?} \quad \overline{\bar{p}} J[x, x]+J_{p}[x, x+w]
$$

In particular, at $\mathrm{x}_{\mathrm{p}}+\mathrm{w}$, only the electron current density must be taken into account. In the space charge zone, in stationary regime and in the absence of recombination, and to one dimension, for the electrons, the continuity equation is given by [10]:

$$
\begin{aligned}
& \frac{1}{e} \frac{\partial J_{n}}{\partial x}+g_{n}(x)=0 \\
& J_{n}=-e \int_{x_{p}+w}^{x_{p}} g_{n}(x) d x
\end{aligned}
$$

After integration we get:

$$
J_{n}=-e(1-R) \Phi_{0}\left(1-e^{-\alpha_{1} w_{1}} e^{-\alpha_{2} w_{2}}\right) e^{-\alpha_{1} x_{p}}
$$

we ignore the reflection at the interface (the dielectric constants of both sides of the junction are identical at the junction [4]).

From the equations (8) and (26), we get the expression of the internal quantum efficiency of the space charge zone (formula 27), which describes the contribution of the carriers generated in this zone (figure1) and collected by the $p-n$ junction:

$$
\eta_{z c e}=\left(1-e^{-\alpha_{1} w_{1}} e^{-\alpha_{2} w_{2}}\right) e^{-\alpha_{1} x_{p}}
$$

\subsection{Structure of a Homojunction P-p-n Grown on Substrate with Window Layer (P-Type): The Model of $G a_{1-y} A l_{y} S b_{P} / G a_{1-x} I n_{x} S b_{p} / G a_{1-x} I n_{x} S b_{n} / G a S b_{N}$}

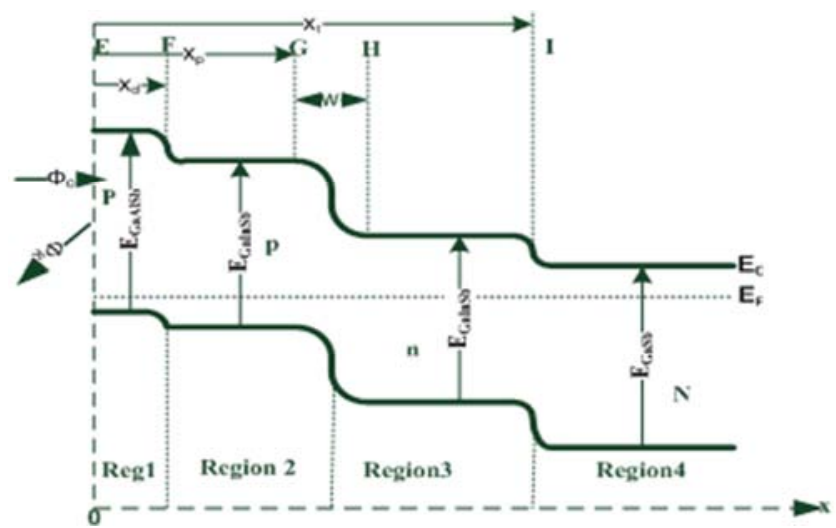

Figure 2. Energy band diagram of $G a_{l-y} A l_{y} S b_{P} / G a_{l-x} I n_{x} S b_{p} / G a_{l-x} I n_{x} S b_{n}$ homojunction grown on $\mathrm{GaSb}_{N}$ substrate.

In this case we will assume that the junction is located between the p-doped layer and the n-doped layer. The geometrical parameters are shown at Figure2. The photocurrent density in the space charge zone and the base are calculated in the same manner as in 2.1. The results differ from a pre coefficient, due to the presence of the first layer $\mathrm{P}$ (area EF Figure2) used as a window layer. As against, the photocurrent densities in regions 1 and 2 will change. We will consider, in the calculations of the photocurrent density in these two regions, the recombinations at surface of the first front layer and at interface of the two layers.

In the region2 (FG area Figure2), the expression of the 
current density resulting from the diffusion of electrons is:

$$
J n_{2}=\left.e D n_{2} \frac{d \Delta n_{2}}{d x}\right|_{x=x_{p}}
$$

This current density is obtained from the following continuity equations [4]:

$$
\begin{gathered}
\frac{d^{2} \Delta n_{1}}{d x^{2}}-\frac{\Delta n_{1}}{\left(L n_{1}\right)^{2}}=-\frac{\alpha_{1}(1-R) \Phi_{0} e^{-\alpha_{1} x_{p}}}{D n_{1}} \\
\frac{d^{2} \Delta n_{2}}{d x^{2}}-\frac{\Delta n_{2}}{\left(L n_{2}\right)^{2}}=-\frac{\alpha_{2}(1-R) \Phi_{0} e^{-\left(\alpha_{1}-\alpha_{2}\right) x_{d}} e^{-\alpha_{2} x_{p}}}{D n_{2}}
\end{gathered}
$$

where $\mathrm{Ln}_{1}$ et $\mathrm{Ln}_{2}$ are the diffusion lengths of electrons, respectively in regions 1 and $2, \alpha_{1}$ and $\alpha_{2}$ are the absorption coefficients of the layers 1 and $2, \mathrm{Dn}_{1}$ and $\mathrm{Dn}_{2}$ the electron diffusion coefficients in regions 1 and $2, \Delta \mathrm{n}_{1}$ and $\Delta \mathrm{n}_{2}$ are the variations of electrons charge densities in the regions 1 and 2 .

The solutions of these equations are in the form:

$$
\begin{gathered}
\Delta n_{1}(x)=A_{1} e^{-x / L n_{1}}+B_{1} e^{x / L n_{1}}+K_{1} e^{-\alpha_{1} x} \\
\text { with } K_{1}=-\frac{\left(L n_{1}\right)^{2} \alpha_{1}(1-R) \Phi_{0}}{D n_{1}\left[\left(\alpha_{1}\right)^{2}\left(L n_{1}\right)^{2}-1\right]} \\
\Delta n_{2}(x)=A_{2} e^{-x / L n_{2}+B_{2} e^{x / L n_{2}}+K_{2} e^{-\alpha_{2} x}} \\
\text { with } K_{2}=-\frac{\left(L n_{2}\right)^{2} \alpha_{2}(1-R) \Phi_{0} e^{-\left(\alpha_{1}-\alpha_{2}\right) x_{d}}}{D n_{2}\left[\left(\alpha_{2}\right)^{2}\left(L n_{2}\right)^{2}-1\right]}
\end{gathered}
$$

The constants $A_{1}, B_{1}, A_{2}$ and $B_{2}$ are obtained from the following boundary conditions [4]:

$$
\begin{gathered}
\frac{d \Delta n_{1}}{d x}=\frac{S n_{1}}{D n_{1}} \Delta n_{1} \text { for } x=0 \\
\Delta n_{1}=0 \text { for } x=x_{d} \\
D n_{2} \frac{d \Delta n_{2}}{d x}=D n_{1} \frac{d \Delta n_{1}}{d x}+\Delta n_{2} S n_{2} \text { for } x=x_{d} \\
\Delta n_{2}=0 \text { for } x=x_{p}
\end{gathered}
$$

The $\mathrm{Jn}_{2}$ distribution of current density of the electrons in region2 (FG area Figure2) is calculated by:

$$
\begin{aligned}
& J n_{2}=-\frac{e(1-R) \Phi_{0} \alpha_{2} L n_{2} e^{-\left(\alpha_{1}-\alpha_{2}\right) x_{d}}}{\left[\left(\alpha_{2}\right)^{2}\left(\operatorname{Ln}_{2}\right)^{2}-1\right]}
\end{aligned}
$$

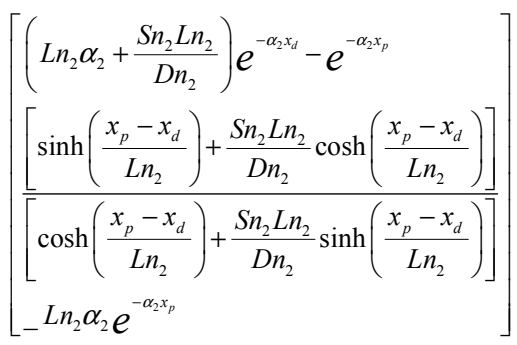

$$
\begin{aligned}
& -\frac{e(1-R) \Phi_{0} \alpha_{1} L n_{1}}{\left[\left(\alpha_{1}\right)^{2}\left(L n_{1}\right)^{2}-1\right]}
\end{aligned}
$$

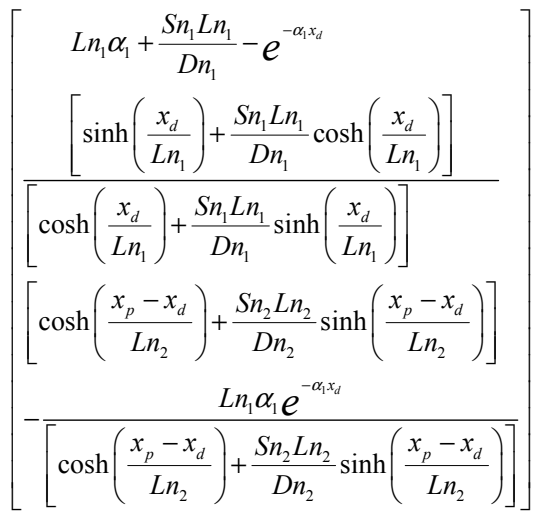

From equations (8) and (39), we derive the expression of the internal quantum efficiency of the transmitter (Formula 40), which describes the contribution of electrons generated in the transmitter and in the window layer (FG and EF zones figure2) and collected by the p-n junction.

$$
\begin{aligned}
& \eta_{F}=\frac{\alpha_{2} L n_{2} e^{-\left(\alpha_{1}-\alpha_{2}\right) x_{d}}}{\left[\left(\alpha_{2}\right)^{2}\left(L n_{2}\right)^{2}-1\right]} \\
& {\left[\begin{array}{l}
\left(L n_{2} \alpha_{2}+\frac{S n_{2} L n_{2}}{D n_{2}}\right) e^{-\alpha_{2} x_{d}}-e^{-\alpha_{2} x_{p}} \\
{\left[\sinh \left(\frac{x_{p}-x_{d}}{L n_{2}}\right)+\frac{S n_{2} L n_{2}}{D n_{2}} \cosh \left(\frac{x_{p}-x_{d}}{L n_{2}}\right)\right]} \\
{\left[\begin{array}{l}
\left.\cosh \left(\frac{x_{p}-x_{d}}{L n_{2}}\right)+\frac{S n_{2} L n_{2}}{D n_{2}} \sinh \left(\frac{x_{p}-x_{d}}{L n_{2}}\right)\right] \\
L n_{2} \alpha_{2} e^{-\alpha_{2} x_{p}}
\end{array}\right]}
\end{array}\right]} \\
& +\frac{\alpha_{1} L n_{1}}{\left[\left(\alpha_{1}\right)^{2}\left(L n_{1}\right)^{2}-1\right]}
\end{aligned}
$$

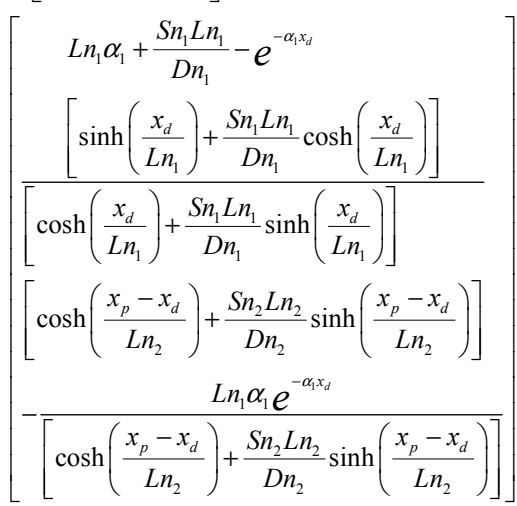




\section{Spectral Responses}

We call spectral response, the number of charge carriers (electrons or holes) created by each photon. It depends on the wavelength and is between 0 to 1 . It is also called quantum efficiency. The same information is provided by the determination of the spectral sensitivity, which is expressed in $\mathrm{A} / \mathrm{W}$.

Theoretical models are applied to various devices corresponding to best photodetectors in the range of wavelength $0,78 \mu \mathrm{m}$, to $2,6 \mu \mathrm{m}$. We report the best results of the influence of photoelectric parameters (diffusion lengths and recombination velocity) and geometrical parameters (thickness of the transmitter and window layer) on the internal quantum efficiency or sensitivity given by each case of the used theoretical model. The work is devoted on the heterostructures based on $\mathrm{Ga}_{1-\mathrm{x}} \mathrm{In}_{\mathrm{x}} \mathrm{Sband}_{\mathrm{Ga}_{1-\mathrm{y}}} \mathrm{Al}_{\mathrm{y}} \mathrm{Sb}(\mathrm{x}=0.18$, $\mathrm{y}=0.08$ ) deposited on $\mathrm{GaSb}_{\mathrm{N}}$ substrate.

\subsection{Influence of the Electron Recombination Velocity at the Transmitter Surface (The Models$$
G a_{1-x} I n_{x} S b_{p} / G a_{1-x} I n_{x} S b_{n} / G a S b_{N} \text { and, } G a_{1-y} A l_{y} S b_{p} /
$$$$
\left.G a_{1-x} I n_{x} S b_{n} / G a S b_{N}\right)
$$

The figure3.a and figure3.b show the influence of the recombination velocity at surface on the internal quantum efficiency versus photon energy for a $\mathrm{Ga}_{1-\mathrm{x}} \mathrm{In}_{\mathrm{x}} \mathrm{Sb}_{\mathrm{p}} / \mathrm{Ga}_{1-\mathrm{x}} \mathrm{In}_{\mathrm{x}} \mathrm{Sb}_{\mathrm{n}} / \mathrm{GaSb}_{\mathrm{N}}$ homojunction (figure $3 \mathrm{a}$ ) and a $\mathrm{Ga}_{1-\mathrm{y}} \mathrm{Al}_{\mathrm{y}} \mathrm{Sb}_{\mathrm{p}} / \mathrm{Ga}_{1-\mathrm{x}} \mathrm{In}_{\mathrm{x}} \mathrm{Sb}_{\mathrm{n}} / \mathrm{GaSb}_{\mathrm{N}}$ heterojunction (figure $3 \mathrm{~b}$ ).

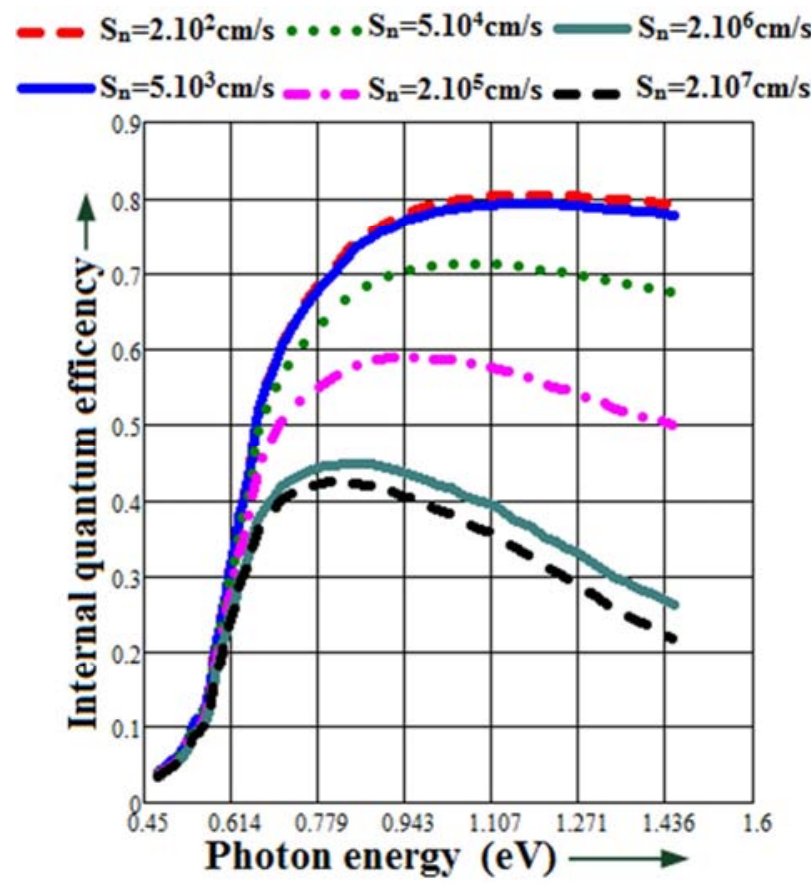

Figure 3a). Quantum efficiency for different recombination velocities values vs. photon energy of $G a_{1-x} I n_{x} S b_{p} / G a_{1-x} I n_{x} S b_{n} / G a S b_{N}$ homojunction $\left(L n_{1}=0.5 \mu \mathrm{m}, L p_{2}=5 \mu \mathrm{m}, L p_{3}=6 \mu \mathrm{m}, x_{p}=1.2 \mu \mathrm{m}, x_{t}=7 \mu \mathrm{m}, w=0.7 \mu \mathrm{m}\right)$.

There is a strong decrease in the internal quantum efficiency with increasing the recombination velocity for $\mathrm{Sn}$ values ranging from $5.10^{3} \mathrm{~cm} / \mathrm{s}$ to $2.10^{6} \mathrm{~cm} / \mathrm{s}($ Figure 3$)$. Below
$5.10^{3} \mathrm{~cm} / \mathrm{s}$ and, beyond $2.10^{6} \mathrm{~cm} / \mathrm{s}$, the recombinations at surface have practically no influence on the quantum efficiency. This phenomenon is related to the fact that the recombination effect at surface is less preponderant on the recombination effect in volume, whose recombination velocity is of the order of $\mathrm{Dn} / \mathrm{Ln}[3]$.

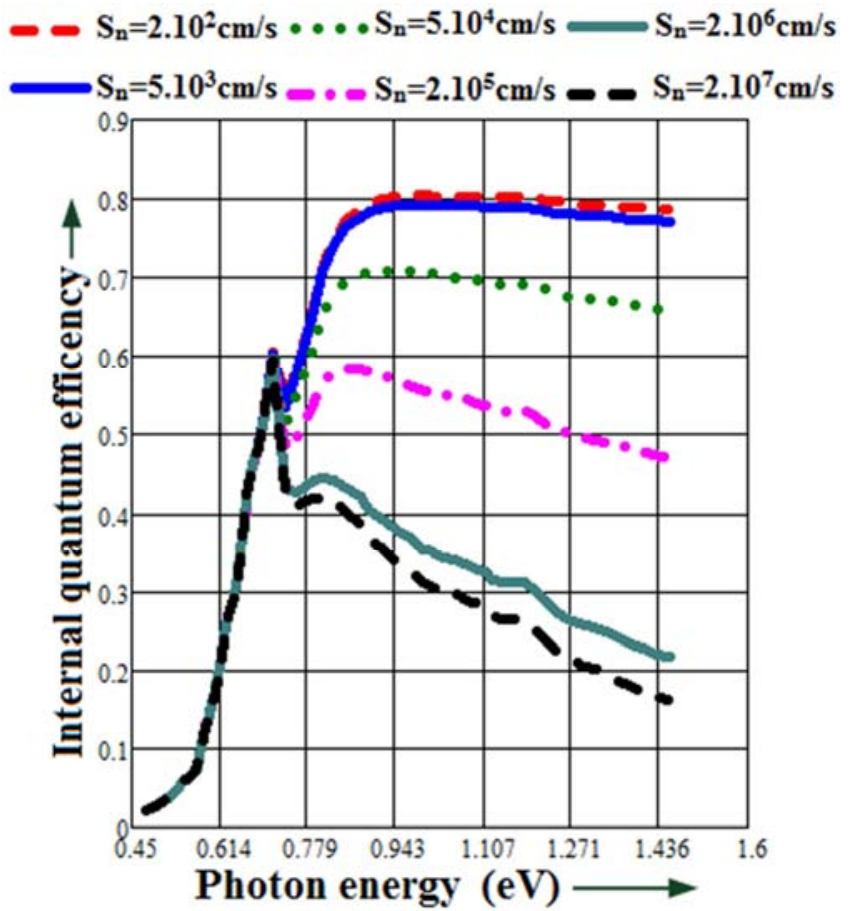

Figure 3b). Quantum efficiency for different recombination velocities values vs. photon energy of $G a_{1-y} A l_{y} S b_{P} / \quad G a_{1-x} I n_{x} S b_{n} / G a S b_{N}$ heterojunction $\left(L n_{1}=0.5 \mu \mathrm{m}, L p_{2}=5 \mu \mathrm{m}, L p_{3}=6 \mu \mathrm{m}, x_{p}=1.2 \mu \mathrm{m}, x_{t}=7 \mu \mathrm{m}, w=0.7 \mu \mathrm{m}\right)$.

This result gives us information about the possible limits of the recombination velocities at surface and at interface for these models of devices. On figure 3b, we observe two peaks, of which the first corresponds to the absorption in the base and the second that of the transmitter.

Indeed, the $\mathrm{Ga}_{1-\mathrm{y}} \mathrm{Al}_{\mathrm{y}} \mathrm{Sb}_{\mathrm{p}}$ material, having higher gap energy than that of the $\mathrm{Ga}_{1-\mathrm{x}} \mathrm{In}_{\mathrm{x}} \mathrm{Sb}_{\mathrm{n}}$, remains transparent to energy values less than its gap energy, allowing thereby the $\mathrm{Ga}_{1-\mathrm{x}} \mathrm{In}_{\mathrm{x}} \mathrm{Sb}_{\mathrm{n}}$ material to absorb at first. The decrease in quantum efficiency, just after the maximum of the second peak, is related to recombination phenomenon at surface that prevent a portion of the electrons generated in the vicinity of the surface of the transmitter to contribute to the photocurrent. This recombination phenomenon at surface is due to a large number of the recombinant centers, to an important density of states of interfaces related to defects of structure and impurities.

\subsection{Influence of the Transmitter Thickness on the Quantum Efficiency (The Models Ga $a_{1-x} I n_{x} S b_{p} / G a_{1-x} I n_{x} S b_{n} / G a S b_{N}$ and, $\left.G a_{1-y} A l_{y} S b_{p} / G a_{1-x} I n_{x} S b_{n} / G a S b_{N}\right)$}

The figure4.a and figure 4.b show the influence of the thickness of the transmitter on the internal quantum efficiency versus photon energy for $\mathrm{a} \mathrm{Ga}_{1-\mathrm{x}} \mathrm{In}_{\mathrm{x}} \mathrm{Sb}_{\mathrm{p}} / \mathrm{Ga}_{1-\mathrm{x}} \mathrm{In}_{\mathrm{x}} \mathrm{Sb}_{\mathrm{n}} / \mathrm{GaSb}_{\mathrm{N}}$ 
homojunction (figure4a) and a

$\mathrm{Ga}_{1-\mathrm{y}} \mathrm{Al}_{\mathrm{y}} \mathrm{Sb}_{\mathrm{p}} / \mathrm{Ga}_{1-\mathrm{x}} \mathrm{In}_{\mathrm{x}} \mathrm{Sb}_{\mathrm{n}} / \mathrm{GaSb}_{\mathrm{N}}$ heterojunction (figure $4 \mathrm{~b}$ ).

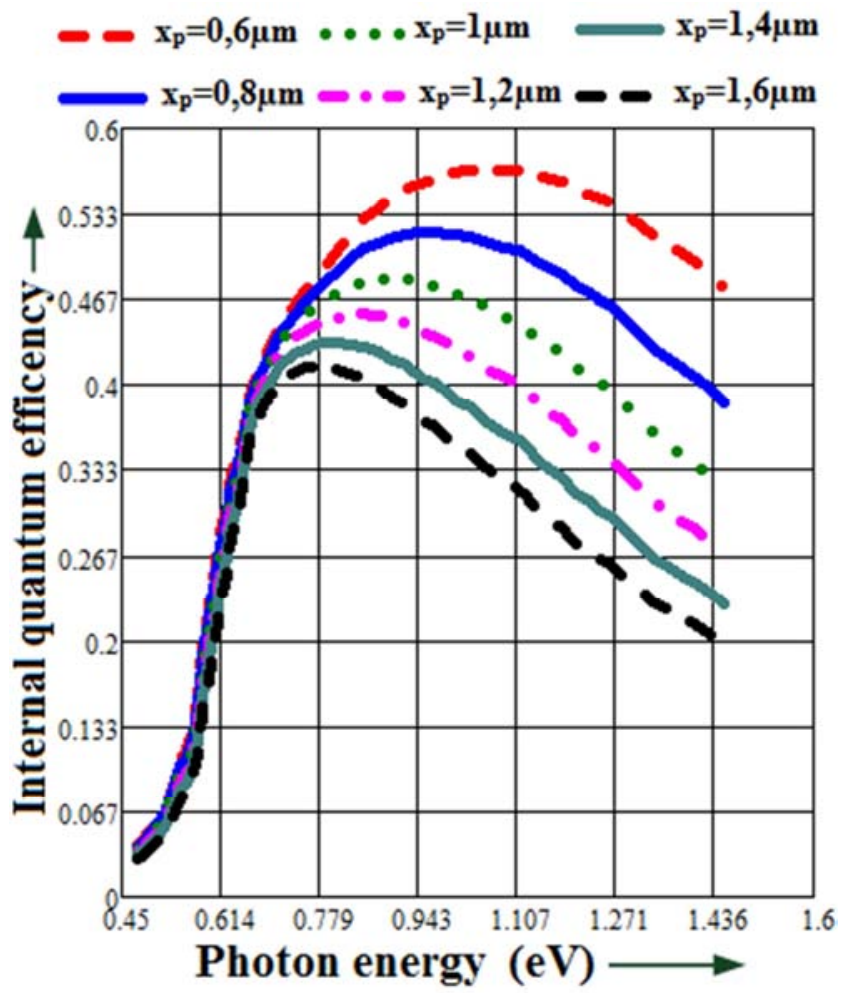

Figure 4a. Quantum efficiency for different values of the thickness vs. photon energy of $G a_{l_{-1}} A l_{y} S b_{P} / G a_{l_{-x}} I n_{x} S b_{p} / G a_{l_{-x}} I n_{x} S b_{n} / G a S b_{N} \quad$ heterojunction $\left(S_{n 1}=2.10^{6} \mathrm{~cm} / \mathrm{s}, L n_{1}=0.5 \mu \mathrm{m}, L p_{2}=5 \mu \mathrm{m}, L p_{3}=6 \mu \mathrm{m}, x_{t}=7 \mu \mathrm{m}, w=0.7 \mu \mathrm{m}\right)$.

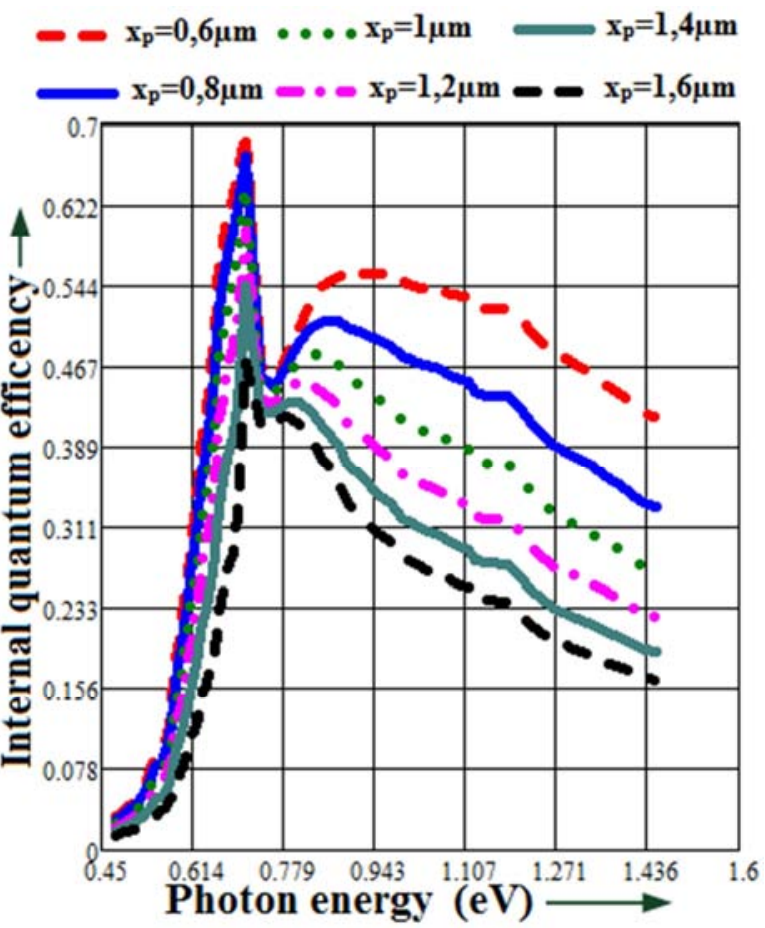

Figure 4b. Quantum efficiency for different values of the thickness vs. photon energy of $G a_{l-x} A l_{y} S b_{P} / G a_{l-x} I n_{x} S b_{p} / G a_{l-x} I n_{x} S b_{n} / G a S b_{N} \quad$ homojunction $\left(S_{n 1}=2.10^{6} \mathrm{~cm} / \mathrm{s}, L n_{1}=0.5 \mu \mathrm{m}, L p_{2}=5 \mu \mathrm{m}, L p_{3}=6 \mu \mathrm{m}, x_{t}=7 \mu \mathrm{m}, w=0.7 \mu \mathrm{m}\right)$.

Whatever model considered, an increase in signal is observed when we decreases the transmitter thickness. However, we note that for low thicknesses, the maximum is obtained, to high energies for the homojunction (figure4a) while for the heterojunction model (figure4b), the maximums are obtained with low energies, corresponding to wavelength of about $1,75 \mu \mathrm{m}$.

For $\mathrm{Ga}_{1-\mathrm{x}} \mathrm{In}_{\mathrm{x}} \mathrm{Sb}_{\mathrm{p}} / \mathrm{Ga}_{1-\mathrm{x}} \mathrm{In}_{\mathrm{x}} \mathrm{Sb}_{\mathrm{n}} / \mathrm{GaSb}_{\mathrm{N}}$ model, this decrease of quantum efficiency is related to the fact that at high thicknesses, only the carriers (electrons) generated near the junction, manage to achieve the junction and to contribute to the photocurrent, while for low thicknesses, most of the carriers generated near the surface contribute to the photocurrent. The phenomenon observed in the model $\mathrm{Ga}_{1-\mathrm{y}} \mathrm{Al}_{\mathrm{y}} \mathrm{Sb}_{\mathrm{p}} / \mathrm{Ga}_{1-\mathrm{x}} \mathrm{In}_{\mathrm{x}} \mathrm{Sb}_{\mathrm{n}} / \mathrm{GaSb}_{\mathrm{N}}$ is due to the fact that the $\mathrm{Ga}_{1-\mathrm{y}} \mathrm{Al}_{\mathrm{y}} \mathrm{Sb}_{\mathrm{p}}$ layer remains transparent to low energies allowing thereby, a strong generation of holes at grassroots level and which will contribute to the photocurrent, while in the model $\mathrm{Ga}_{1-\mathrm{x}} \mathrm{In}_{\mathrm{x}} \mathrm{Sb}_{\mathrm{p}} / \mathrm{Ga}_{1-\mathrm{x}} \mathrm{In}_{\mathrm{x}} \mathrm{Sb}_{\mathrm{n}} / \mathrm{GaSb}_{\mathrm{N}}$ few photons achieve the base. The slight decrease in signal, observed immediately after the maximum, is attributed to recombination phenomenons.

\subsection{Influence of the Widow Layer Thickness on the Sensitivity (The Model $G a_{1-y} A l_{y} S b_{P} / G a_{1-X} I n_{X} S b_{p} / G a_{1-x} I n_{x} S b_{n} / G a S b_{N}$ )}

Figure 5 shows the influence of the window layer thickness on the sensitivity versus photon energy for a $\mathrm{Ga}_{1-\mathrm{y}} \mathrm{Al}_{\mathrm{y}} \mathrm{Sb}_{\mathrm{P}} / \mathrm{Ga}_{1-\mathrm{X}} \mathrm{In}_{\mathrm{X}} \mathrm{Sb}_{\mathrm{p}} / \mathrm{Ga}_{1-\mathrm{x}} \mathrm{In}_{\mathrm{x}} \mathrm{Sb}_{\mathrm{n}} / \mathrm{GaSb}_{\mathrm{N}}$ homojunction.

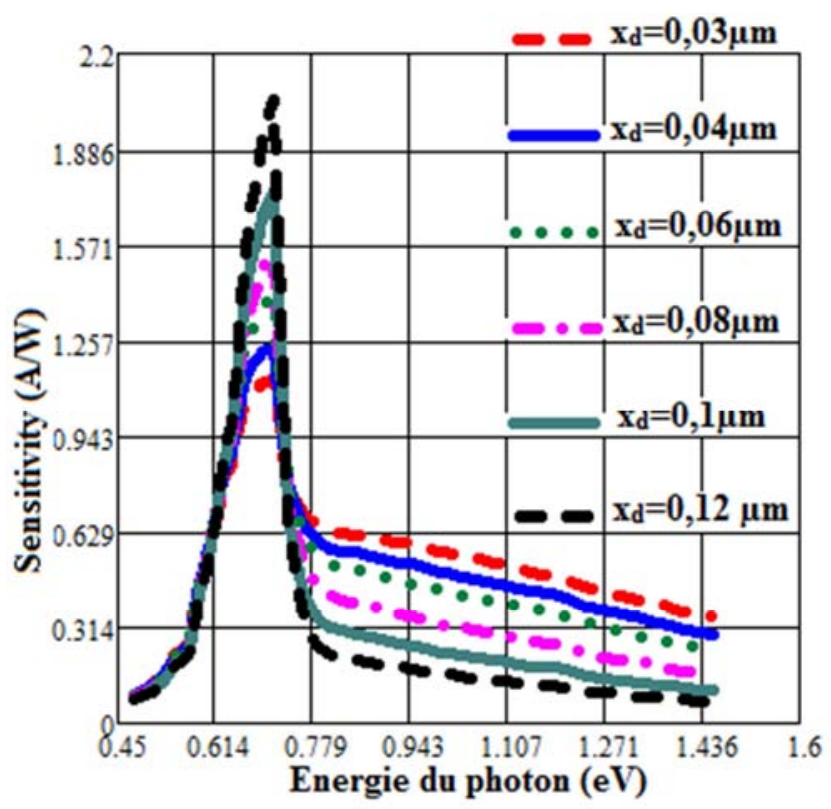

Figure 5. Sensitivity for different values of the window layer thickness vs. photon energy of $G a_{1-y} A l_{y} S b_{P} / G a_{1-x} I n_{x} S b_{p} / G a_{1-x} I n_{x} S b_{n} / G a S b_{N}$ homojonction $\left(S_{n 1}=2.10^{6} \mathrm{~cm} / \mathrm{s}, S_{n 2}=2.10^{3} \mathrm{~cm} / \mathrm{s}, L n_{1}=0.5 \mu \mathrm{m}, \mathrm{Ln}_{2}=1 \mu \mathrm{m}, L p_{3}=5 \mu \mathrm{m}, L p_{4}=6 \mu \mathrm{m}\right.$, $\left.x_{p}=0.4 \mu \mathrm{m}, x_{t}=7 \mu \mathrm{m}, w=0.7 \mu \mathrm{m}\right)$.

The sensitivity analysis for different values of the thickness of the window layer shows a net improvement in the sensitivity of the device with the increase in the thickness of the window layer. However, this increase suggests a small value of the thickness of the emitter $\left(x_{p}=0,4 \mu \mathrm{m}\right.$ Figure 5$)$. It is 
possible to achieve sensitivity of the order of $2.05 \mathrm{~A} / \mathrm{W}$ for a thickness of the window layer of the order of $0.12 \mu \mathrm{m}$ and that of the emitter of the order of $0.28 \mu \mathrm{m}$. For these thickness values, the internal quantum efficiency is of the order of $96 \%$ for photon energy of $0.72 \mathrm{eV}$ either in the absorption spectrum of the near infrared. Indeed, the window layer remains transparent to the energy photon flux lower than its bandgap energy, whereas the low value of the emitter thickness leads to a low absorption in the emitter, which allows to the maximum of photons to be absorbed in the base, and in the space charge area. The photons arriving in the base and in the space charge area generate free carriers, which in turn, contribute to the photocurrent, resulting in a net improvement of the sensitivity of the device.

\subsection{Comparative Study of the Sensitivity of Different Models of Photodetectors Versus the Radiation Energy}

Figure6 shows the sensitivity of photodetectors devices versus the energy of the radiation. The rising edge of the sensitivity curves is abrupt. This result is due to the rapid increase of the absorption coefficient with the photon energy, typical of a direct gap material.

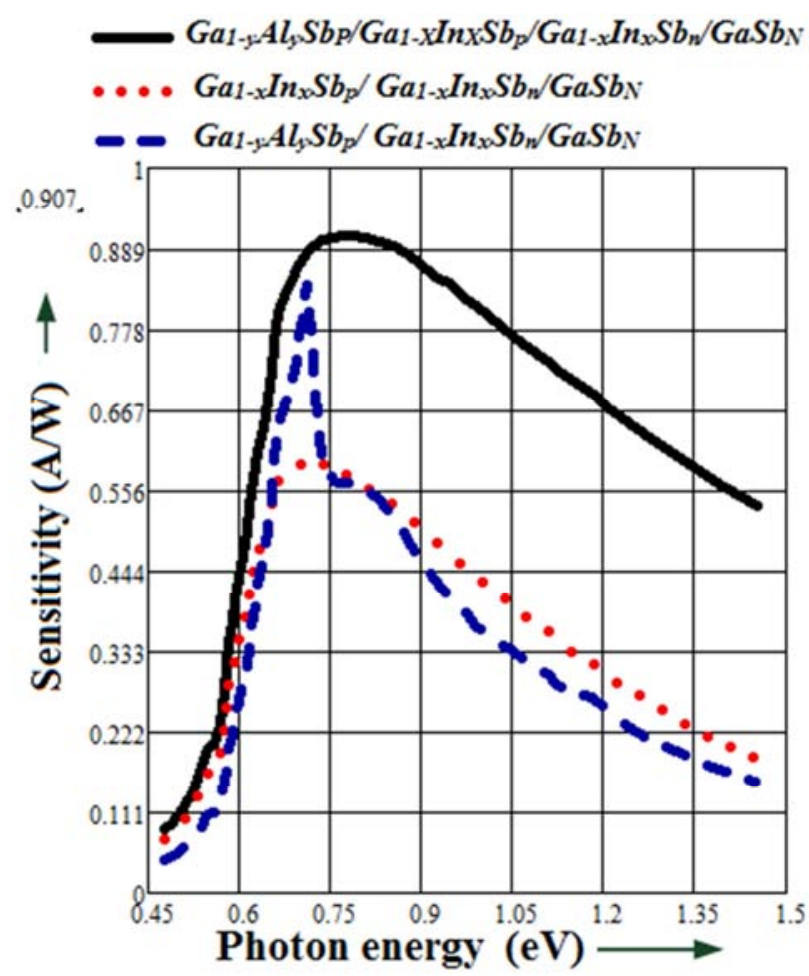

Figure 6 . Sensitivity of photodetectors devices versus the energy of the radiation $\left(S_{n 1}=2.10^{6} \mathrm{~cm} / \mathrm{s}, S_{n 2}=2.10^{3} \mathrm{~cm} / \mathrm{s}, L n_{1}=0.5 \mu \mathrm{m}, L n_{2}=1 \mu \mathrm{m}, L p_{3}=5 \mu \mathrm{m}\right.$, $\left.L p_{4}=6 \mu m, x_{d}=0.1 \mu m, x_{p}=1.2 \mu m, x_{t}=7 \mu m, w=0.7 \mu m\right)$.

The decrease of the signal observed immediately after the maximum, is attributed to recombination phenomenons at surface. We note that the position of the maximum of the sensitivity of the photodetectors depends on the model; that is to say, at the transition energy of bandgap of the layers which compose them.

This position of the maximum, lies practically at an energy
$\mathrm{E}_{0}=0,71 \mathrm{eV}$, corresponding to a wavelength $\lambda_{\max }=1,75 \mu \mathrm{m}$ slightly less than the cutoff wavelength defined by $\lambda_{\mathrm{c}}(\mu \mathrm{m})=$ $1.24 / \mathrm{E}_{0}(\mathrm{eV})$. The study of the sensitivity of the photodetectors models shows that the $\mathrm{Ga}_{1-\mathrm{y}} \mathrm{Al}_{\mathrm{y}} \mathrm{Sb}_{\mathrm{P}} / \mathrm{Ga}_{1-\mathrm{x}} \mathrm{In}_{\mathrm{x}} \mathrm{Sb}_{\mathrm{p}} / \mathrm{Ga}_{1-\mathrm{x}} \mathrm{In}_{\mathrm{x}} \mathrm{Sb}_{\mathrm{n}} / \mathrm{GaSb}_{\mathrm{N}}$ model has a maximum sensitivity of about $0,907 \mathrm{~A} / \mathrm{W}$ substantially greater than that of $\mathrm{Ga}_{1-\mathrm{x}} \mathrm{In}_{\mathrm{x}} \mathrm{Sb}_{\mathrm{p}} / \mathrm{Ga}_{1-\mathrm{x}} \mathrm{In}_{\mathrm{x}} \mathrm{Sb}_{\mathrm{n}} / \mathrm{GaSb}_{\mathrm{N}}(0,593 \mathrm{~A} / \mathrm{W})$ and the $\mathrm{Ga}_{1-\mathrm{y}} \mathrm{Al}_{\mathrm{y}} \mathrm{Sb}_{\mathrm{P}} / \mathrm{Ga}_{1-\mathrm{x}} \mathrm{In}_{\mathrm{x}} \mathrm{Sb}_{\mathrm{n}} / \mathrm{GaSb}_{\mathrm{N}} \quad(0,84 \mathrm{~A} / \mathrm{W})$. This difference is related to the presence of the $\mathrm{Ga}_{1-\mathrm{y}} \mathrm{Al}_{\mathrm{y}} \mathrm{Sb}_{\mathrm{P}}$ window layer, which in the first time, remains transparent to low energies, for better absorption in the transmitter and in the base. It plays an important role in the reduction of recombinations at surface and at the interface thus allowing a maximum of minority carriers to be collected.

\section{Conclusion}

In this article, we analyzed the performance of photoelectric detectors corresponding to three different models: $\mathrm{a} \mathrm{Ga}_{1-\mathrm{x}} \mathrm{In}_{\mathrm{x}} \mathrm{Sb}_{\mathrm{p}} / \mathrm{Ga}_{1-\mathrm{x}} \mathrm{In}_{\mathrm{x}} \mathrm{Sb}_{\mathrm{n}} / \mathrm{GaSb}_{\mathrm{N}}$ homojunction and a $\mathrm{Ga}_{1-\mathrm{y}} \mathrm{Al}_{\mathrm{y}} \mathrm{Sb}_{\mathrm{p}} / \mathrm{Ga}_{1-\mathrm{x}} \mathrm{In}_{\mathrm{x}} \mathrm{Sb}_{\mathrm{n}} / \mathrm{GaSb}_{\mathrm{N}}$ heterojunction deposited on the $\mathrm{GaSb}_{\mathrm{N}}$ substrate, and a $\mathrm{Ga}_{1-\mathrm{y}} \mathrm{Al}_{\mathrm{y}} \mathrm{Sb}_{\mathrm{P}} / \mathrm{Ga}_{1-\mathrm{X}} \mathrm{In}_{\mathrm{X}} \mathrm{Sb}_{\mathrm{p}} / \mathrm{Ga}_{1-\mathrm{x}} \mathrm{In}_{\mathrm{x}} \mathrm{Sb}_{\mathrm{n}} / \mathrm{GaSb}_{\mathrm{N}}$ homojunction deposited on the $\mathrm{GaSb}_{\mathrm{N}}$ substrate, with $\mathrm{Ga}_{1-\mathrm{y}} \mathrm{Al}_{\mathrm{y}} \mathrm{Sb}_{\mathrm{P}}$ as window layer. This analysis is based on the photon energy of the incident light, and the photoelectric and geometrical parameters of the various devices. In each model, we determined the internal quantum efficiency that we simulated to appreciate the photoelectric behavior of the different models. Theoretical analysis of the spectral response of these photodetectors models has allowed us to understand their conduction mechanisms and the limits of their performances. The improvement of the spectral response requires the use of a thin transmitter. However, we note that to obtain a high internal quantum efficiency at low energies (wavelengths between $0,78 \mu \mathrm{m}$ to $2,6 \mu$ meither in the absorption spectrum of the near infrared), it is necessary to use average thicknesses around $1,2 \mu \mathrm{m}$. Analysis of the results shows that the sensitivity is much important, with the low incidences, through a $\mathrm{Ga}_{1-\mathrm{y}} \mathrm{Al}_{\mathrm{y}} \mathrm{Sb}_{\mathrm{p}} / \mathrm{Ga}_{1-\mathrm{x}} \mathrm{In}_{\mathrm{x}} \mathrm{Sb}_{\mathrm{n}} / \mathrm{GaSb}_{\mathrm{N}}$ heterojunction than through a $\mathrm{Ga}_{1-\mathrm{x}} \mathrm{In}_{\mathrm{x}} \mathrm{Sb}_{\mathrm{p}} / \mathrm{Ga}_{1-\mathrm{x}} \mathrm{In}_{\mathrm{x}} \mathrm{Sb}_{\mathrm{n}} / \mathrm{GaSb}_{\mathrm{N}}$ homojunction for both structures. The recombinations at surface and at volume significantly limit the performances of $\mathrm{Ga}_{1-\mathrm{x}} \mathrm{In}_{\mathrm{x}} \mathrm{Sb}_{\mathrm{p}} / \mathrm{Ga}_{1-\mathrm{x}} \mathrm{In}_{\mathrm{x}} \mathrm{Sb}_{\mathrm{n}}$ and $\mathrm{Ga}_{1-\mathrm{y}} \mathrm{Al}_{\mathrm{y}} \mathrm{Sb}_{\mathrm{p}} / \mathrm{Ga}_{1-\mathrm{x}} \mathrm{In}_{\mathrm{x}} \mathrm{Sb}_{\mathrm{n}}$ deposited on the $\mathrm{GaSb}_{\mathrm{N}}$ substrate. The window layer of the $\mathrm{Ga}_{1-\mathrm{y}} \mathrm{Al}_{\mathrm{y}} \mathrm{Sb}_{\mathrm{P}} / \mathrm{Ga}_{1-\mathrm{x}} \mathrm{In}_{\mathrm{x}} \mathrm{Sb}_{\mathrm{p}} / \mathrm{Ga}_{1-\mathrm{x}} \mathrm{In}_{\mathrm{x}} \mathrm{Sb}_{\mathrm{n}} / \mathrm{GaSb}_{\mathrm{N}}$ plays an important role in reducing these recombinations allowing thereby to get a better sensitivity around $0.907 \mathrm{~A} / \mathrm{W}$ ( $\mathrm{Ln}$ $=1 \mu \mathrm{m}, \quad \mathrm{x}_{\mathrm{p}}=1.2 \mu \mathrm{m}$ and $\left.\mathrm{x}_{\mathrm{d}}=0.1 \mu \mathrm{m}\right)$. Ultimately, the performance of an infrared photodetector device, beyond its photoelectric and geometrical parameters, depends on the corresponding model and consequently the $\mathrm{Ga}_{1-\mathrm{y}} \mathrm{Al}_{\mathrm{y}} \mathrm{Sb}_{\mathrm{P}} / \mathrm{Ga}_{1-\mathrm{X}} \mathrm{In}_{\mathrm{X}} \mathrm{Sb}_{\mathrm{p}} / \mathrm{Ga}_{1-\mathrm{x}} \mathrm{In}_{\mathrm{x}} \mathrm{Sb}_{\mathrm{n}}$ homojunction grown on $\mathrm{GaSb}_{\mathrm{N}}$ substrate is the model allowing to obtain better detection in the range between $0,78 \mu \mathrm{m}$ to $2,6 \mu \mathrm{m}$ (absorption spectrum of the near infrared). 


\section{References}

[1] J. Chen, Y. Zhou, Z. Xu, J. Xu, Q. Xu, H. Chen, L. He. InAs/GaSb type-II superlatice mid-wavelength infrared focal plane array detectors grown by molecular beam epitaxy. Journal of Crystal Growth 378, 596-599, (2013)

[2] L. Gouskov, M. Boustani, G. Bougnot, C. Gril, A. Joullie et al. Photodétecteurs à base de Ga1-xAlxSb dans la gamme 1,3-1,6 $\mu \mathrm{m}$. Revue de physique Appliquée, 18(12), 781-782, (1983).

[3] P. Viktorovitch. Passivation des sémiconducteurs III-V. Revue Phys.Appl 25 895-914, (1990).

[4] B. MBOW, A. MEZERREG, N. REZZOUG, and C. LLINARES. Spectral Responses in Near-infrared of III-V Photodetectors. Phys, sat. sol (a) 141, 511-525, (1994).

[5] YUAN. TIAN et al. The analysis of the performance for Photodetectors. Phys, sat. sol(a) 174, 414, (1999).

[6] A Joullié, F. De Anda, P. Salsac. Diffusion du zinc dans GaAlSb et application à la photodétection infrarouge. Revue Phys. Appl. 19223-230 (1984).

[7] C. Touzi, Z. Chine, T. Boufaden, B. El Jani. Etude de la réponse spectacle des cellules photovoltaïques à base de GaN.Phys, Chem. News 1 69-72, (2001).

[8] S. N. SINGH and P. K. SINGH. Exact calculation of back surface recombination velocity and its influence on quantum efficiency of n+-p-p+ structure based silicon cells. Proc IEEE 1629-1631, (1988).

[9] L. Nam, M. Rodot et al. Réponse spectacle de photopiles de haut rendement au silicium multicristallin. Journal de physique III EDP Sciences, 2 (7), 1305-1316, (1992).

[10] H Mathieu \& H Fanet. Physique des sémiconducteurs et des composants électroniques, Dunod: 6ème édition

[11] J. Bozec et G. Rolland. Evaluation de la longueur de diffusion par la méthode EBIC dans les piles solaires à l'AsGa et application à l'environnement spatial. Revue de Physique Appliquée, 21 (8), 509-514, (1986). 